\title{
Residual atmosphere in vacuum fluorescent displays
}

\author{
S.H. Finkelshtein ${ }^{1}$, V.M. Sorokin ${ }^{2}$, S.A. Rakitin ${ }^{1}$, V.P. Sevostyanov ${ }^{1}$ \\ ${ }^{1}$ Saratov State University \\ 83, Astrakhanskaya, Saratov, 410026, Russia.E-mail: acm@intsar.com \\ ${ }^{2}$ Institute of Semiconductor Physics, NAS Ukraine \\ 45, Prospekt Nauki, Kyiv, 252028, Ukraine.E-mail: vsorokin@isp.kiev.ua
}

\begin{abstract}
This paper is devoted to problems of gassing in vacuum fluorescent displays (VFD). Technique of qualitative and quantitative analysis of residual atmosphere in VFDs is presented. Also, dynamics of residual gas pressure under different modes of VFD operation is considered.
\end{abstract}

Key words: gassing, vacuum fluorescent display, residual atmosphere, pumping-out.

Paper received 23.09.99; revised manuscript received 15.12.99; accepted for publication 17.12.99.

\section{Introduction}

Investigation of residual atmosphere composition in vacuum fluorescent displays (VFDs) seems to be of interest from several standpoints. Firstly, as well known [1, 2], VFD is a vacuum device of low-voltage cathodolumines-cence with electron energy of c. $100 \ldots 200 \mathrm{eV}$. It means that generation of non-equilibrium carriers on surface of phosphor particles and emitting recombination in phosphor bulk take place under deeply non-equilibrium conditions. This feature makes low-voltage cathodoluminescence to be very sensitive to processes on «phosphor surface - residual atmosphere» boundary (adsorption, desorption, heterogeneous reactions, etc.), including the electron stimulated ones. These circumstances determine efficiency of phosphor operation in VFDs [3-5]. Secondly, it is known [6] that oxide cathode with direct heating is also very sensitive to residual atmosphere, since its emitting activity and durability define performances and reliability of VFD [7]. Thirdly, last decade was marked by intensive studies of cathodoluminescent displays with field emission cathodes (FED) [8-10]. It is clear that the above problem of device reliability and durability is actual for field emission cathode, too.

Thus, it is obvious that further progress in sphere of development and mass production of VFDs and FEDs requires complex research including investigations of residual atmosphere in vacuum fluorescent displays [11].

This paper represents main results of experimental studies of residual atmosphere in VFD under traditional technological operations such as pumping-out, degassing and getter spraying. As an object stock-produced display of P-403 type was investigated.

\section{Experimental studies}

Experiments with VFDs were performed on the plant described in [12] (Fig. 1).

Before VFD opening (stem destruction) chambers $M$ and $K$ were pumped out (Fig. 1 ) by $M H$ pump, chamber $K$ was preliminarily degassed, then cock $K_{1}$ was turned off in order to decrease system sensitivity. Measuring and recording partial pressures were performed under constant pressure due to sides soakage. This effect was taken into account by comparing with preliminary results obtained without stem destruction.

With gassing investigations in VFD under operation conditions (both cathode, anode and grid are live), tube was pumped out through partly turned on cock $K_{1}$ that maintains constant pressure at $10^{-6} \ldots 10^{-7}$ Torr and still keeps omegatron sensor sensitivity high enough. Then mass-spectrometer of IPDO-1 type was set up for determined mass and, at last, controlling electrodes of VFD were turned on. by

Pressure $p_{1}$ in VFD without sprayed getter is determined

$p_{1}=\frac{V_{0}}{V_{1}}\left(p_{2}-p_{1}\right)+p_{2}$,

where $p_{2}, p_{0}$ are pressures in $M+K+\mathrm{VFD}$ and $M+K ; V_{0}, V_{1}$ are volumes of $M+K$ chambers and VFD, respectively.

\section{Overall argon pressure determination}

Upon completion of the $M$-chamber pumping-out down to pressure $p_{M}=1.28 \cdot 10^{-8}$ Torr, pump H-250 was cut off from $M$-chamber that in turn was connected to $K$-chamber. As a 


\section{S.H. Finkelshtein et al.: Residual atmosphere in vacuum fluorescent displays}

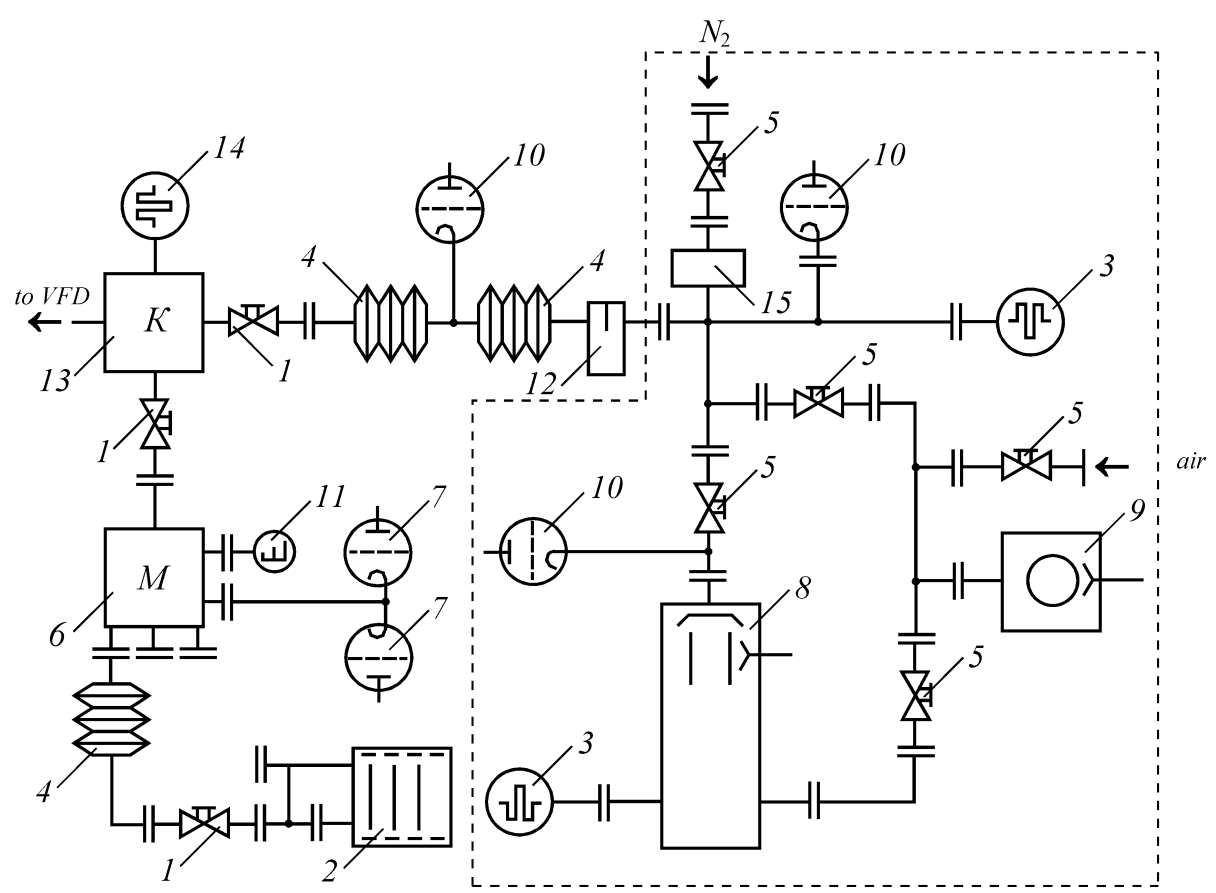

Fig. 1. Vacuum scheme of the working plant: 1 - commutation cocks; 2 - magnetodischarge pump NORD-250; 3 - filled-system transducers PMT-2; 4 - silphon junctions; 5 - commutation cocks of pumping post (PORA-1); 6 - measuring chamber $M ; 7$ - filled-system transducer MI27; 8 - diffusion pump (DP); 9 - forevacuum mechanical pump (FP); 10 - filled-system transducer PMI-2; 11 - partial pressure sensor RMO4S; 12 - superhighvacuum lock (L); 13 - chamber $K ; 14$ - filled-system transducer PMT-2 of chamber $K$; 15 - nitrogen supply-line filter

result of sides soakage, pressure in system $M+K$ was linearly raised during $25 \mathrm{~min}$ from $1.8 \cdot 10^{-7}$ to $5 \cdot 10^{-7}$ Torr. Specified time period was used for carrying out the experiment.

As pressure reached $5 \cdot 10^{-7}$ Torr, stem destruction was performed (pumped out VFD without getter - P-403, \#1), it led to pressure leap up to $1.6 \cdot 10^{-5}$ Torr, then within $5 \mathrm{~min}$ pressure dropped down to $1.5 \cdot 10^{-6}$ Torr (Fig. 2, 1).

Stem destruction in pumped out and trained VFD with

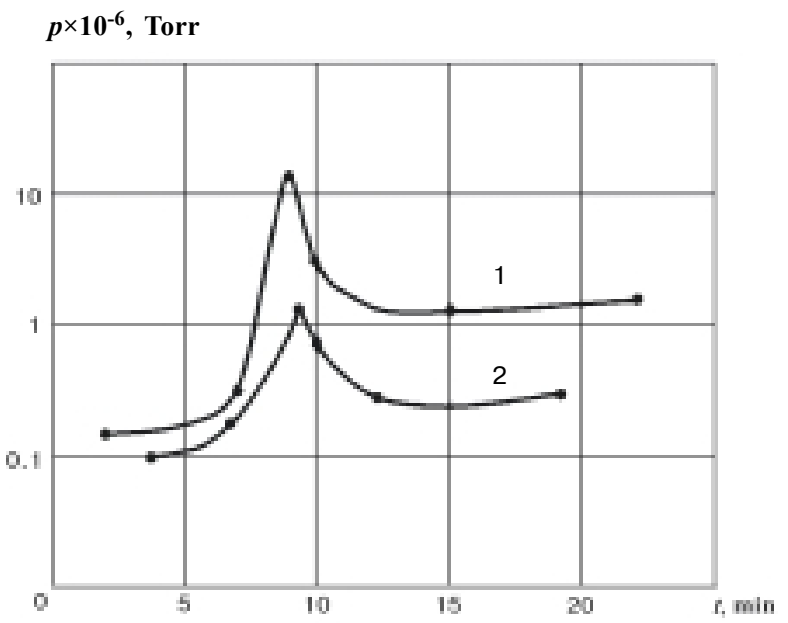

Fig. 2. Pressure changes in system after VFD stem destruction: 1 pumped out without getter (P-403, \#1);2 - pumped out and trained with sprayed getter (P-403, \#2) sprayed getter (P-403, \#2) gave rise to initial pressure increase up to $1.5 \cdot 10^{-6}$ Torr, but within next 5 min pressure reverted to $3.2 \cdot 10^{-7}$ Torr (Fig. 2, 2). Obviously, it can be explained by gassing from glass chip. Thus, in trained VFD overall pressure (excluding Ar partial pressure) may be estimated by value lesser than $3 \cdot 10^{-7}$ Torr.

As for VFD without getter, pressure in tube, i.e. pressure provided by pumping machine, may be estimated using Eq. (1) as $10^{-2}$ Torr.

Since there was no Ar peak in the $M+K$ system before stem destruction, Ar partial pressure in VFD tube may be estimated by Ar pressure $p_{\mathrm{Ar}}$ in the system $M+K+\mathrm{VFD}$ (3.5.1 $10^{-8}$ Torr for P-403, \#1 and $5 \cdot 10^{-8}$ Torr for P-403, \#2) taking into account that VFD tube volume $3 . . .4$ orders of magnitude lesser than that of the $M+K$.

\section{Residual gases in the VFD tube}

Mass-spectra of P-403, \#1 VFD before and after opening are shown in Fig. 3, a. Based on absence of Ar in system $M+K$ and overall pressure range from $1.6 \cdot 10^{-5}$ Torr (stem destruction) to $10^{-6}$ Torr (standard mode), residual atmosphere in VFD tube without getter consists of $\mathrm{CO}\left(1.2 \cdot 10^{-2}\right.$ Torr $) ; \mathrm{H}_{2}$ (8.10 $0^{-3}$ Torr); $\mathrm{CH}_{4} ; \mathrm{CO}_{2} ; \mathrm{Ar} ; \mathrm{H}_{2} \mathrm{O}$; hydrocarbons $\mathrm{C}_{2} \mathrm{H}_{4}$ (all corresponds to degree of $3 \cdot 10^{-6}$ Torr); hydrocarbons with $\mathrm{cm} / \mathrm{e}=74 \ldots 80$ (c. $10^{-6}$ Torr).

Investigations of residual pressure in display with sprayed getter (P-403, \#2) entails some troubles, because of 


\section{S.H. Finkelshtein et al.: Residual atmosphere in vacuum fluorescent displays}

lesser slope of overall pressure curve (Fig. 2, 2) than in case of P-403, \#1. It means that display's pumping activity is involved, at least, for some gases of residual atmosphere. Mass-spectra before (dotted line) and after (solid line) stem destruction are presented in Fig. 3, b. Taking into account the same arguments as well as for P-403, \#1 display, residual atmosphere in VFD with sprayed getter appears to be consisted of $\mathrm{CO}\left(<6.1 \cdot 10^{-8}\right.$ Torr $) ; \mathrm{H}_{2}\left(>6 \cdot 10^{-7}\right.$ Torr $) ; \mathrm{CH}_{4}$ ( $<7 \cdot 10^{-9}$ Torr) $; \mathrm{CO}_{2}\left(<3 \cdot 10^{-9}\right.$ Torr $) ; \mathrm{Ar}$ (c. $3.5 \cdot 10^{-5}$ Torr); $\mathrm{H}_{2} \mathrm{O}$ $\left(>4.6 \cdot 10^{-10}\right.$ Torr). Thus, it is clear that residual atmosphere in VFD tube after pumping out, training and getter spraying has pronounced reducing nature. In this case, overall pressure (excluding Ar) is mainly determined by partial pressure of $\mathrm{H}_{2}$ and, perhaps, carbon oxide (II).

\section{Dynamics of residual atmosphere in VFD}

It is expected that display turning on should result in gassing due to both thermal desorption (cathode) and electronstimulated processes (anode, grid).

It is worth to note that electron-stimulated desorption of vapors is more convenient to investigate in tubes without sprayed getter, since presence of «internal» pumping activity greatly reduces system sensitivity. Thereupon, studies were carried out on both tubes pumped out directly on the working plant (P-403, \#1) and tubes with sprayed getter
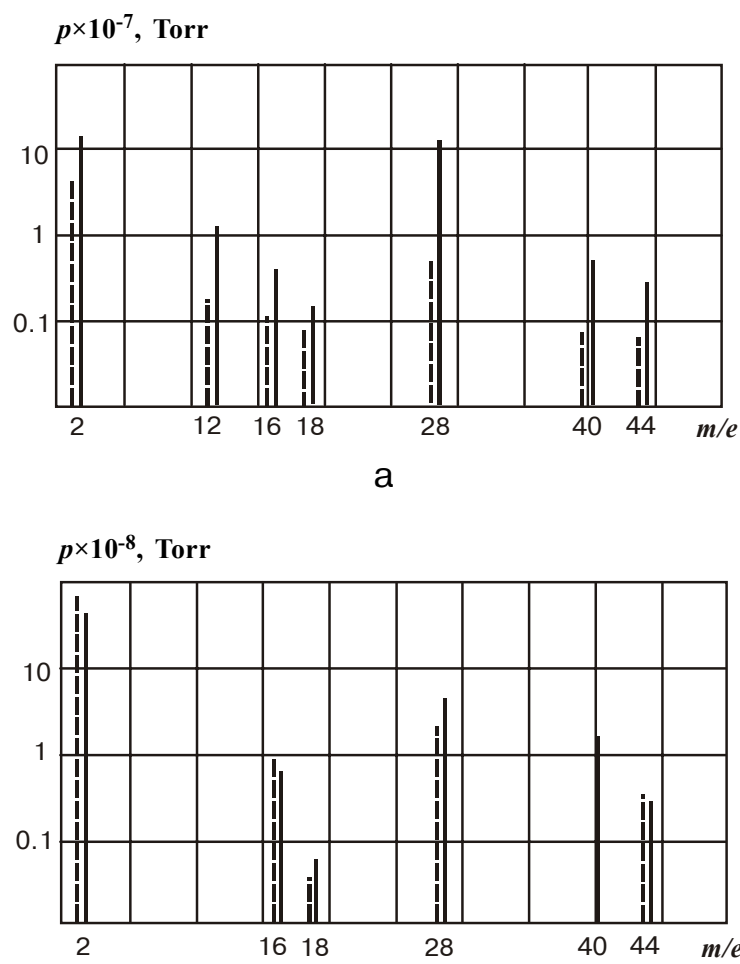

b

Fig. 3. Mass-spectrum of system before (dotted line) and after (solid line) display opening: a - display pumped out on the working plant (P-403, \#1); b - one with sprayed getter and pumped out on industrial semi-automatic pump (P-403, \#2) that were pumped out on industrial semi-automatic pump (P-403, \#2).

In the latter case, method of «accumulation» was used. It means that studied display operates in isolated chamber $K$, then cock $K_{1}$ (Fig. 1) turns on for chamber $M$ and atmosphere analysis starts to run. Background experiment consists in holding turned off display in isolated chamber $K$ during the same period with further cock turning on and partial pressure analysis.

The main results of performed experiments may be summarized as follows. After cathode heating starts, residual atmosphere is enriched by molecular hydrogen, carbon oxides (II) and (IV); water and methane peaks increase weakly (degree of $10^{-10}$ Torr), as shown in Fig. 4. Presence of positive bias voltage on grid $(+15 \mathrm{~V})$ leads to significant rise of $\mathrm{H}_{2}$ and $\mathrm{CO}$ peaks and extremely weak changes in intensities of $\mathrm{CO}_{2}, \mathrm{H}_{2} \mathrm{O}$ and $\mathrm{CH}_{4}$ peaks.

It should be noted that partial pressure changes for all the above gases after cathode and grid turning on stays negligible in comparison with previously formed atmosphere.

It is quite different case, when positive bias voltage $(+27 \mathrm{~V})$ is applied to phosphor (Fig. 5, a,b). As shown, massspectrum of evolved gases remains qualitatively the same $\left(\mathrm{H}_{2}, \mathrm{CO}, \mathrm{CO}_{2}, \mathrm{H}_{2} \mathrm{O}\right.$ and $\left.\mathrm{CH}_{4}\right)$, though in quantitative terms additional partial pressures are comparable or even greater than «background» level.

Thus, one can conclude that, firstly, qualitative and quantitative composition of evolved gases is independent of chemical nature of phosphor $(\mathrm{ZnO}, \mathrm{ZnS},[\mathrm{Zn}, \mathrm{Cd}] \mathrm{S})$ and technological prehistory of the sample (table 1). Secondly, display warming up makes phosphor gassing under electron bombardment 3...15 times as low as in cold device (Fig. 5, a and 5, b). Thirdly, form of pressure leaps in moment of turning on display with sprayed getter has distinguished nature (Fig. 6). It is interesting to point out correlation between leaps of overall pressure and hydrogen partial pressure demonstrating steep slopes at moments of VFD «turning on» and «off». Mentioned effects, according to [13], may be used as quantitative measure of gases evolving from surface $\left(p_{1}-p_{0}\right)$ and volume $\left(p_{2}-p_{0}\right)$ of VFD. Fourthly, as shown above, after pumping out, thermal treatment and getter spraying overall pressure in VFD (excluding Ar) equals to c. $10^{-7}$ Torr and is mainly determined by hydrogen partial pressure

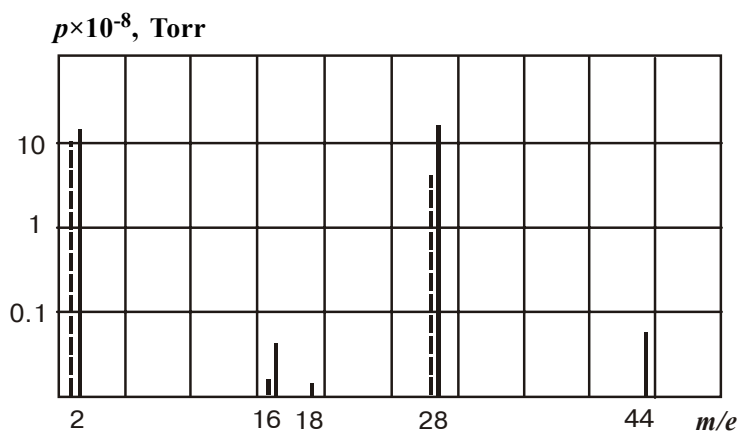

Fig. 4. Mass-spectrum of system before (dotted line) and after (solid line) cathode turning on, for VFD pumped out on the working plant (P-403, \#1) 


\section{S.H. Finkelshtein et al.: Residual atmosphere in vacuum fluorescent displays}
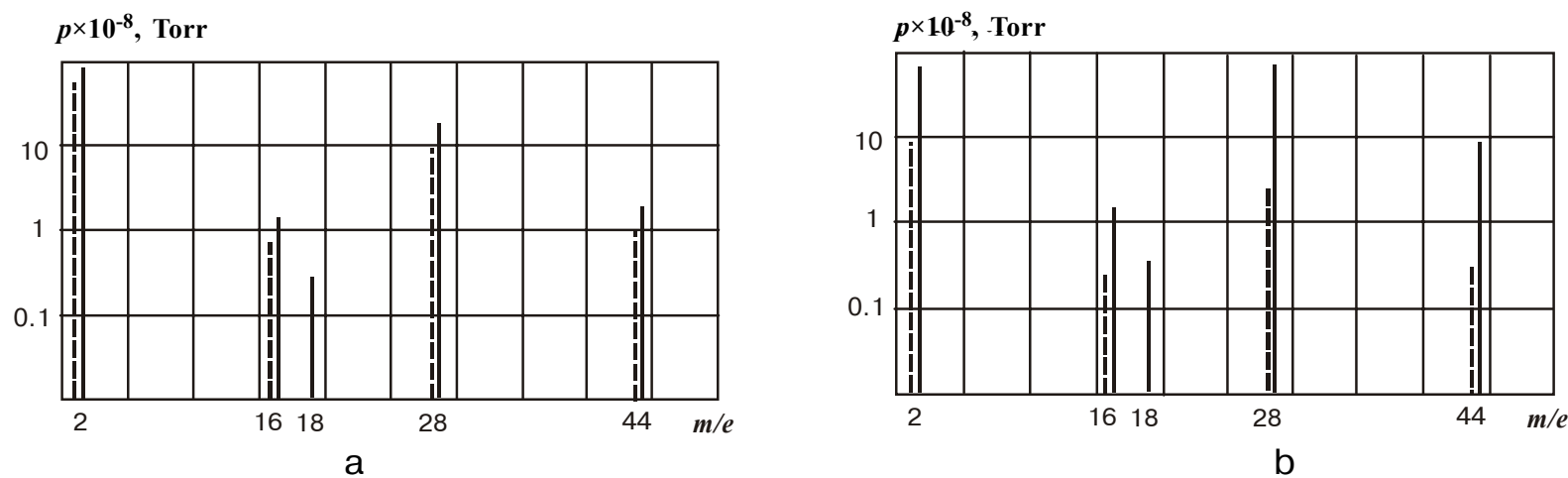

Fig. 5. Mass-spectrum of system before (dotted line) and after (solid line) applying positive bias voltage on display phosphor: a - display pumped out on the working plant (P-403, \#1); b - one with sprayed getter and pumped out on industrial semi-automatic pump (P-403, \#2)

that is generally typical for receiver-amplifier tubes [14]. Difference of the latter mainly consists in gassing source (phosphor in VFD case). These differences are quite «leveled» by present standard pumping technology (pumping-out on semi-automatic pump with thermal treatment and further Ba getter spraying). However, this situation is changed dramatically for FED that has surface area to tube volume ratio 10 times as high as typical VFD. It results in «poor» (in comparison with receiver-amplifier tubes) vacuum in FED and fast device degradation that takes place in practice.

Table 1. Partial pressure changes in VFD P-403, \#2

\begin{tabular}{l|cllll}
\hline Display & \multicolumn{5}{|c}{ Partial pressures $\left(p_{\alpha} \cdot 10^{-7}\right.$, Torr $)$ of gases with $(\mathrm{m} / \mathrm{e})_{\mathrm{a}}$ : } \\
\cline { 2 - 6 } operation mode & 2 & 16 & 18 & 28 & 44 \\
\hline Turned on & 20 & 0.78 & 0.27 & 4 & 0.25 \\
Turned off & 18.7 & 0.6 & 0.18 & 3 & 0.19 \\
Pressure difference & 1.13 & 0.18 & 0.09 & 1 & 0.06 \\
\hline
\end{tabular}

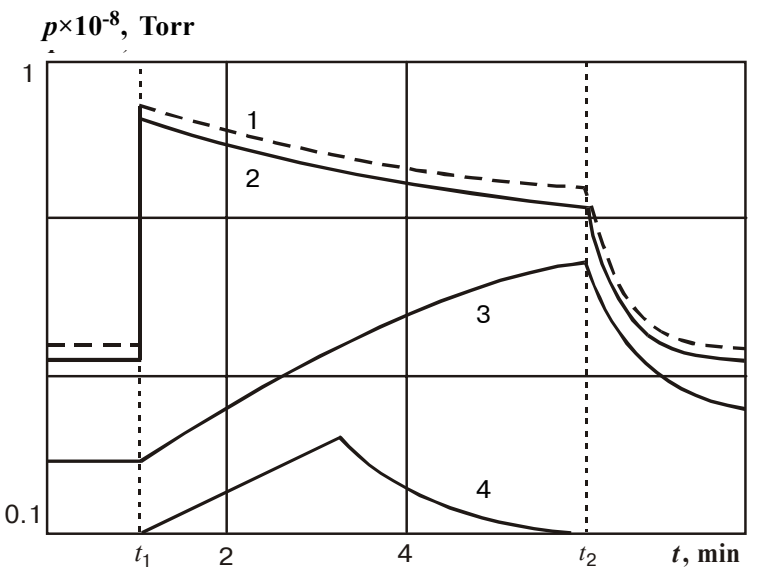

Fig. 6. Partial pressure dynamics under turning on (moment $t_{1}=1 \mathrm{~min}$ ) and off (moment $t_{2}=6 \mathrm{~min}$ ) display with sprayed getter: 1 - overall pressure in system; $2-\mathrm{H}_{2}$ partial pressure; 3 - $\mathrm{CO}$ partial pressure; $4-\mathrm{H}_{2} \mathrm{O}$ partial pressure
Thus, during VFD pumping out in frames of typical technological processes overall pressure in tube is determined by Ar partial pressure (c. $10^{-5}$ Torr). In this case, overall pressure of all the other gases does not exceed c. $10^{-7}$ Torr. Residual atmosphere has reducing nature. Dynamics of atmosphere in VFD tube is determined by processes of $\mathrm{H}_{2}$ and $\mathrm{CO}$ desorption on phosphor surface under electron bombardment or warming up with further redistribution of adsorption and desorption flows between getter and phosphor.

\section{References}

1. E.G. Bylander, Surface Effects on the Low-Energy Cathodoluminescence of Zinc Oxide // J. Appl. Phys., 49(3), p. 1188-1195 (1978).

2. B.V. Abalduyev, A.O. Dmitrienko, Low-voltage Cathodoluminescent Displays // Electronnaya Tekhnika. Ser. 4, 1, p. 12-15 (1972) [in Russian].

3. B.I. Gorfinkel, A.O. Dmitrienko, S.H. Finkelshtein, Factors Determining Effect of Low-voltage Cathodoluminescence of Crystalophosphors // Neorg. Materialy, 29 (10), p. 1379-1382 (1993) [in Russian].

4. A.O. Dmitrienko, S.P. Shmakov, Efficiency of Low-voltage Cathodoluminescence of Modified $\mathrm{ZnO}$ Crystalophosphors // Neorg. Materialy, 30 (4), p. $572-574$ (1994) [in Russian].

5. S.A. Rakitin, A.O. Dmitrienko, S.H. Finkelshtein, AES and Cathodoluminescence of $\mathrm{ZnO}-\mathrm{Zn}$ Phosphor in VFD // $4^{\text {th }}$ Int. Conference on Actual Problems of Electronic Instrument Engineering. Novosibirsk, Sep 23-26, 1998: Book of Proceedings, 1, p. 102-103.

6. V.Ya. Moyzhes, Physical Processes in Oxide Cathode, 479 p., M.: Nauka (1968) [in Russian].

7. B.I. Gorfinkel, B.V. Abalduyev, R.S. Medvedev et al., Low-voltage Cathodoluminescent Displays, 112 p., M.: Radio i Svyaz (1983) [in Russian].

8. H. Bechtel, W. Czarnojan, M. Haase, D. Wadow, Phosphor Degradation under Electron Excitation with Varying Anode Voltage / $/ 1^{\text {st }}$ Int. Conference on the Science and Technology of Display Phosphors. San Diego, Nov 14-16, 1995: Book of Extended Abstracts. - p. 259.

9. T. Trottier, H. Swart, S. Jones, J. Sebastian, A Comparison of the Degradation Mechanisms of Sulfide and Oxysulfide Phosphors for Use in Field-Emission Displays // $1^{\text {st }}$ Int. Conference on the Science and Technology of Display Phosphors. San Diego, Nov 
S.H. Finkelshtein et al.: Residual atmosphere in vacuum fluorescent displays

14-16, 1995: Book of Extended Abstracts. - p. 263

10. H. Swart, J. Sebastian, S. Jones, T. Trottier, Surface Reactions of $\mathrm{ZnS}: \mathrm{Cu}, \mathrm{Al}, \mathrm{Au}$ Powders under Electron Bombardment // $1^{\text {st }}$ Int. Conference on the Science and Technology of Display Phosphors. San Diego, Nov 14-16, 1995: Book of Extended Abstracts. - p. 267.

11. B.V. Abalduyev, V.Ya. Filipchenko, S.H. Finkelshtein et al., Lowvoltage Cathodoluminescent Display as System // Seminar on Thin-film Light Emitting Structures and Their Applications. Book of Abstracts, p. 66-67, Rovno (1987) [in Russian].
12. S.H. Finkelshtein, S.A. Rakitin, V.P. Sevostyanov et al., A Plant for Atmosphere Analysis in Vacuum Devices and Research Technique // PTE. 1, p. 142-144 (1999).

13. L.A. Peterman, Gas Desorption under Electron Bombardment // Residual Gases in Electron Tubes, ed. G.D. Glebov, p. 139-145, M.: Energiya (1967) [in Russian].

14. P. della Porta, Present Knowledge on Residual Gases in Electron Tubes // Tech. Reports TR/TRG, firm Saes (1965). 